Available online at GSC Online Press Directory

GSC Biological and Pharmaceutical Sciences

e-ISSN: 2581-3250, CODEN (USA): GBPSC2

Journal homepage: https://www.gsconlinepress.com/journals/gscbps

(REVIEW ARTICLE)

\title{
Influence of osteoporosis on quality of life and current strategies for its management and treatment
}

\author{
Ashiq Kanwal 1,2, Rehman Khurrum ${ }^{2}$, Ashiq Sana ${ }^{3}$ and Sundus Ahlam ${ }^{2 *}$ \\ ${ }^{1}$ University College of Pharmacy, University of the Punjab Lahore, Pakistan \\ ${ }^{2}$ Lahore Pharmacy College, Lahore Medical and Dental College, Lahore Pakistan \\ ${ }^{3}$ Microbiology and Molecular Genetics Department, University of the Punjab Lahore, Pakistan
}

Publication history: Received on 24 October 2017; revised on 09 November 2017; accepted on 13 November 2017

https://doi.org/10.30574/gscbps.2017.1.2.0051

\begin{abstract}
Osteoporosis is a silent disease which is more common among women and elderly people. Drastic increase in the incidents of osteoporotic related fractures is a major health concern these days. It negatively influences the quality of life and not only affects the physical, psychological and social activity of people but also increases the monetary burden, and is one of the major causes of morbidity and mortality. The patients who experience the osteoporotic fractures are often depressed due to chronic pain, restricted mobility, fear of fall, and dependence on others. Globally, the economical burden for treatment is too high. Poor implementation of guidelines regarding the diagnosis of disease and availability of the treatment also affects the patient's quality of life. For better quality of life in patients with osteoporosis; awareness programs, prior diagnosis, accessibility to treatment and patient counseling are necessary. This review is the summarized data, which was taken from published work between 2005 and 2017. Aim of the current review is to highlight the impact of osteoporosis on patient's quality of life and to evaluate the current trends in the management of such life devastating disease. It also focuses on diagnosis and treatment strategies available globally. The data generated in this review may be significant in developing policies regarding prevention of osteoporosis, its management and reduction in the cost burden of treatment.
\end{abstract}

Keywords: Osteoporosis; Quality of life; Socio-economic burden; Management; Treatment

\section{Introduction}

The loss of bone strength and its mass that leads to fragile fractures is associated with the disorder called osteoporosis [1]. The older concept states that there are two types of osteoporosis one is associated with the deficiency of calcium and the other is associated with the deficiency of estrogen at menopause [2]. However, the recent concept implies that the osteoporosis is related to the multiple pathological mechanisms which result in deterioration of bone microarchitectural structure and loss of bone mass [3]. The impact of these osteoporotic fractures on the quality of life is negative, because these fractures not only affect the functional capacity of the patient but also are associated with pain, changes in body posture and musculoskeletal system that limits the physical, social and psychological activities of the patient [4]. In health care, these fractures account for an economic burden of approximately 17-20 billion dollars annually [5]. Quality of life covers the aspects of physical, psychological, and social well-being including the financial issues related to the treatment [6]. It is projected that there will be an increase in number of postmenopausal women with osteoporosis from 1.8 million in year 2010 to 2.1 million in year 2020 [7]. In normal situation, bone undergoes a continuous remodeling process involving resorption of aged bone by osteoclasts and development of new bone is the job of osteoblasts [8]. The imbalance between osteoclast and osteoblast activity results into the osteoporosis[9]. The

\footnotetext{
${ }^{*}$ Corresponding author

E-mail address: ahlam.sundus@ lmdc.edu.pk
}

Copyright (C) 2017 Author(s) retain the copyright of this article. This article is published under the terms of the Creative Commons Attribution Liscense 4.0. 
osteoporosis is associated with the increase bone resorption as compared to the bone formation, which causes increase bone fragility due to loss of bone components [10]. The lack of estrogen results into the postmenopausal osteoporosis, which causes unnecessary bone resorption due to increase expression of several cytokines; this is also known as type I osteoporosis. In postmenopausal osteoporosis primarily loss of bone occurs in trabecular bone in the vertebrae and cortical bone [11]. The senile (type II) osteoporosis usually affects two times more to the people who are more than 70 years of age. In type II osteoporosis bone loss and fragility occurs due to increase in level of parathyroid hormone resulted by age-related vitamin D deficiency, which leads to hypocalcemia. As a result to this, increased bone resorption occurs in order to maintain the level of calcium in body [12]. The type II osteoporosis results into the bone loss and it characteristically involves trabecular and cortical regions, which results into fractures of hip bone, proximal bone of humerus, pelvis and tibia [13]. These fractures are related with poor quality of life and increased mortality and morbidity [14]. The fractures of hip are major public health concern as they increase capital burden for both individuals and society. Every year approximately 200 million people are affected by osteoporosis and 8.9 million fractures are reported worldwide [15]. The frequency of hip fracture has possible extensive geographic discrepancy around the world. The world populations demographics is subjected to change as age of population is increased in the emergent countries, and it is expected that $50 \%$ of hip fractures will happen in Asia by 2050 . By considering the geographical variation policy makers would be able to cut the load of hip fractures in developing countries by adopting proper strategies [16]. The aim of the current review is to highlight the impact of osteoporosis on quality of life and to appraise the current trends in diagnosis, treatment and management strategies of such life devastating disease.

The data for this review was taken from published work between 2005 and 2017. The databases included Google Scholar, Springerlink, Science direct, Pubmed and Medline. To ensure credibility of this review only indexed research and review articles were used.

\section{Influence of osteoporosis on quality of life}

\subsection{Physical activity}

Osteoporosis is associated with the fragility fractures and becomes a major public health concern. Out of all fractures, hip fractures are the major cause of morbidity and present with unpleasant consequences. Globally more elderly population becomes affected by the osteoporosis [17]. Poor physical performance irrespective of vertebral fractures, the past experience of falls and sharp back pain increases the terror of falling among women with osteoporosis [18]. Hip fracture causes not only the pain but also imposes the restriction of movement, especially in the aged people. And this is a upsetting condition with complications ranging from ecstasy to diminish functional activities and death [19]. The osteoporotic fractures and falls are may also be caused by the postural instability or postural distortion. The impact of spinal curvature has played a significant role in the stability failure of posture and osteoporosis [20]. The quality of life in osteoporosis patients is appreciably decreased by the fractures that have been occurred in past at a different places; mostly of spine, upper leg and of hip bone, and it might be included more than one bone[21]. The patient quality of life is worsened by the long-term pain and disability associated with the osteoporotic fractures [22]. In post fracture phase of the osteoporosis there is a significant ambiguity about the incidence, degree and severity of the acute pain and still further about the level of disability, the length of pain period, and at how much extent the daily life is concerned [23]. Decline in postural stability when trip a barrier also challenge the way of walking and is of one the cause of falls [24]. In a study, women from Canada, New Zealand, Australia, and the USA were participated and the results of study shows that the quality of life is decline by the both; existing back pain as well as by the new or aggravated back pain [25].

\subsection{Psychological activity}

Psychological effects include nervousness, fear, depression, reduced self-worth, and social separation in patient experienced the fractures [26]. The osteoporosis and correlation with depression has been studied in last ten years and the results of these studies provide the evidence of negative association between the stress and anxiety with the reduced bone mass density. From the study it is concluded that depression can be occurred by decrease in bone mass density [27]. The quality of life can be decline by the any chronic disease, particularly taking into account the opportunity and the threat of losing independence. The pain can be experienced by the patient before the occurrence of fracture. The chronic pain is even not considered during the vertebral fracture event. The pain may lead to the clinical or subclinical depression [28]. The most of studies showed the association between the depression and bone mineral density and provide the evidence of relationship between the risk of fracture and depression in aged individuals [29]. Patients with vertebral fractures are not able to perform routine activities without support or anybody's help which impacts negatively on the patient's mood during early phase of disease [30]. 


\subsection{Economical burden}

Osteoporosis has an overall negative impact on quality of life of the patient and is a major health concern that is responsible for the monetary load on those who are afraid of and face bone fractures [31]. The economic burden was estimated to be $€ 37$ billion for former and incident fragility fractures where, 5\% of the burden accounted for pharmacological prevention, 66\% for incidental fractures and $29 \%$ for long-term fractures. During 2010, around 1,180,000 quality-adjusted life years lost due to past and incident fracture. It was estimated that 5.5 million men and 22 million women have osteoporosis. The 3.5 million new persistent fragility fractures comprise 520,000 vertebral fractures, 610,000 hip fractures, 560,000 forearm fractures and 1,800,000 other fractures (fractures of the scapula, rib, tibia, fibula, humerus, clavicle, pelvis, sternum and other femoral fractures). As in recent years the pharmacological interventions to prevent the fractures is decreased, and incident of osteoporotic fractures is dramatically increases, there is need to change healthcare policy [32]. Per annum, in USA two million fractures are ascribed to osteoporosis. Around $80 \%$ of these fractures currently paid by Medicare, including $72 \%$ of fracture cost is devoted to hip fractures. The cost of care for osteoporosis is estimated $\$ 25.3$ billion by the year 2025 [33]. Although hip fracture unit cost was the highest, the costs of rib, pelvis, wrist, humerus and sternum fractures should be measured when analyzing the cost of osteoporosis [34]. With direct charge of the disease the indirect expenses, sociologic and psychological impact of fractures should be estimated. knowledge among physicians and health care professionals on osteoporosis should be augmented to reduce the load of the illness as this adversely effects the patient quality of life [35]. The incidence of osteoporosis and reduce bone mass is likely to be amplified up to 61.4 million in 2020. The direct cost of fractures related to osteoporosis in 2005 was estimated to be $\$ 19$ billion, adding $\$ 17$ billion for incident fractures and $\$ 2$ billion for current costs of widespread hip, pelvic and vertebral fractures and this weigh down the U.S. healthcare system. If same health care practice is followed, the direct cost of osteoporosis fractures event is expected to reaching \$25 billion in 2025 increase in almost 50\% from 2005. By these findings it is predicted that noticeable demographic changes expected over the coming two decades [36]. Presently $\$ 12$ to $\$ 18$ billion spent on osteoporosis If healthy living is taken into account by the general public, the amount of money can be cut down by avoiding the fracture care [37]. Now there is ample number of publications on cost-effectiveness analyses of drugs in osteoporosis, has been published in past 6 years. These publications outcome and decisive assessment can help the decision makers to assess the future economic burden and develop better health care interventions [38].

\section{Diagnosis of osteoporosis}

All postmenopausal women should be assessed for osteoporosis because risk of osteoporotic fracture is higher in older women than in older men. Osteoporosis can be evaluated by routine physical examination and testing of bone mineral density by using laboratory radiology techniques is generally should be reserved for patients at maximum risk, including all women above the age of 65, all postmenopausal women having a history of fractures and younger postmenopausal women associated with risk factors. In clinical research evaluation of biomedical markers of bone turnover has been proved helpful [39]. Dual energy X-ray absorptiometry (DXA) scan is used for diagnosis of osteoporosis. Results of DXA scan are generally reported as a 'T' score: if T-score is above - 1 it is normal, for osteopenia, T-score is between -1 and -2.5 standard deviation (SD), and osteoporosis can be defined as T-score at or less than -2.5 standard deviation (SD) [40].

\section{Treatment of osteoporosis}

Lifestyle adjustment, dietary supplementation with calcium and vitamin D, and pharmacologic treatment can recover the bone mass and boost the bone quality. For the management of osteoporosis a multidisciplinary approach is necessary. For reduction of fracture risk non pharmacological approaches can be used complementary with the pharmacological treatment. Calcium and vitamin-D supplementation, fall avoidance, hip protectors and exercise programs commonly used non pharmacological interventions. Adequate calcium is vital for the excellent bone health [33]. "A corrected serum calcium level of 2.4-2.6 mmol/L (9.5-10.5 mg/dL)" is called normal calcium status. The daily calcium intake of $1000 \mathrm{mg} /$ day for men and women less than the age of fifty years and $1200 \mathrm{mg} / \mathrm{day}$ for men and women above the age of fifty years is recommended by National Osteoporosis Foundation [41]. The reduction in fracture risk and improved bone mass can be achieved by using numerous pharmacologic agents which have tolerable side-effect profiles, including the bisphosphonates and the selective estrogen receptor regulators i.e. Raloxifene. Monitoring of fracture risk is essential for the women who have abandon the hormone therapy, as after the withdrawal of estrogen treatment, accelerated bone loss and amplified fracture threat can be occurred [42]. To inhibit the unwarranted bone resorption and enhance bone formation new treatment strategies have been developed. The most novel treatments shows potential against the osteoporosis are the: monoclonal antibody i.e. odanacatib which is a major osteoclast cytokine and cathepsin $\mathrm{K}$ which is a specific inhibitor of the osteoclast protease [43]. 


\section{Management}

Worldwide the fragility fractures gain prime health care concern, and as there is improvement in treatment model of osteoporosis [44]. To maximize the bone quality and minimize the fracture incidence, there is urgent need of improved health care policy as the enormous load is imposed by these osteoporotic fracture on individuals [45]. The pharmaceutical care can also play an important role in the prevention of osteoporosis. Pharmaceutical care in women with osteoporosis increases quality of life as well as overall satisfaction [6]. In the study if the pharmaceutical care is provided to an educated woman with back pain, she had better knowledge about the disease which is helpful in prevention of disease. Similarly, women provided with pharmaceutical care who exercised regularly had better quality of life as compared to educated old women, with previous falls and back pain with no pharmaceutical care is likely to have poorer quality of life. The provision of pharmaceutical care showing that the patients' bone health on the whole can be improved, so policymakers should consider placing a clinical pharmacist in the osteoporosis clinic to provide counseling to improve these outcomes [46]. As the drug experts pharmacist occupy a vital position in many healthcare setups. The pharmacist's function in many setups has been changed to patient oriented pharmaceutical care, over the last 20 years. Pharmacists by recognition of highly threatened patients, especially related to those who are on corticosteroid therapy can help to reduce the burden of osteoporosis. The considerable progress in the management of osteoporosis is achieved by the pharmacist interventions such as to counsel and educate the patient with the drug therapy supervision, and also directs to other medical specialist [47]. The risk of osteoporosis can be reduced by giving the proper knowledge and understanding of the disease to the subject with osteoporosis. The load of osteoporosis and its risk in terms of health outcomes and money can be minimized by the consumption of dairy products [48]. Prior intervention and finding of the earliest fracture is necessary, in most of countries the course of action for the analyzing and management of osteoporosis is available and in spite of the accessibility of treatments with confirmed effectiveness however, execution of guidelines is usually pitiable [49]. Recently specific programs for osteoporosis management include the selective screening and hard line treatment not only helpful in prevention of bone loss and improvement of bone quality but also reduce the risk of fractures rate in population in a short period of time [50]. In order to endorse specific behavioral strategies for osteoporosis avoidance, escalating awareness of osteoporosis should be is of main concern for potential upcoming intervention programs [51].

\section{Conclusion}

Osteoporosis is of major health concern. It is a silent disease which increasingly affects the elderly patients and post menopausal women. The quality of life in patients with osteoporosis is significantly negative. The patient who experienced the osteoporotic fractures become depressed due to chronic pain, restricted mobility, fear of fall, and dependence on others. The economical burden for the treatment of osteoporosis is also very much high. Poor implementation of guidelines regarding to the diagnosis of disease and availability of the treatment also affects the quality of life. Awareness programs, patient counseling and education, prior diagnosis, accessibility to treatment and modification of life style is necessary for positive quality of life in patients with osteoporosis.

\section{Compliance with ethical standards}

\section{Acknowledgments}

Authors like to acknowledge University College of Pharmacy, University of the Punjab, Lahore, Pakistan and Lahore Pharmacy College, Lahore Medical and Dental College, Lahore, Pakistan for their support and encouragement.

\section{Disclosure of conflict of interest}

There is no conflict of interest among authors.

\section{References}

[1] Lorentzon M and Cummings S. (2015). Osteoporosis: the evolution of a diagnosis. Journal of internal medicine, 277 (6), 650-661.

[2] Raisz LG. (2005). Pathogenesis of osteoporosis: concepts, conflicts, and prospects. The Journal of clinical investigation, 115 (12), 3318-3325.

[3] Emkey GR and Epstein S. (2014). Secondary osteoporosis: pathophysiology and diagnosis. Best practice and research Clinical endocrinology and metabolism, 28 (6), 911-935. 
[4] Kuru P, Akyüz G, Cerşit HP, Çelenlioğlu AE, Cumhur A, Biricik Ş, Kozan S, Gökşen A, Özdemir M and Lüleci E. (2014). Fracture history in osteoporosis: risk factors and its effect on quality of life. Balkan medical journal, 31 (4), 295.

[5] Becker DJ, Kilgore ML and Morrisey MA. (2010). The societal burden of osteoporosis. Current rheumatology reports, 12 (3), 186-191.

[6] Lips P and van Schoor NM. (2005). Qol in patients with osteoporosis.Osteoporosis international, 16 (5), $447-455$.

[7] Gauthier A, Kanis JA, Jiang Y, Martin M, Compston JE, Borgström F, Cooper C and McCloskey EV. (2011). Epidemiological burden of postmenopausal osteoporosis in the UK from 2010 to 2021: estimations from a disease model. Archives of osteoporosis, 6 (1-2), 179-188.

[8] Lerner U. (2016). Bone remodeling in post-menopausal osteoporosis. Journal of dental research, 85(7), 584-595.

[9] Tanaka Y, Nakayamada S and Okada Y. (2005). Osteoblasts and osteoclasts in bone remodeling and inflammation. Current Drug Targets-Inflammation and Allergy, 4 (3), 325-328.

[10] Rachner TD, Khosla S and Hofbauer LC. (2011). New horizons in osteoporosis. Lancet, 377 (9773), 1276.

[11] Sipos W, Pietschmann P, Rauner M, Kerschan-Schindl K and Patsch J. (2009). Pathophysiology of osteoporosis. WMW Wiener Medizinische Wochenschrift, 159 (9), 230-234.

[12] Duque G and Troen BR. (2008). Understanding the mechanisms of senile osteoporosis: new facts for a major geriatric syndrome. Journal of the American Geriatrics Society, 56 (5), 935-941.

[13] Kamel HK. (2006). Postmenopausal Osteoporosis. Journal of Managed Care Pharmacy, 12 (6 Supp A), S4-S9.

[14] Dennison E, Mohamed MA and Cooper C. (2006). Epidemiology of osteoporosis.Rheumatic Disease Clinics, 32 (4), 617-629.

[15] Pisani P, Renna MD, Conversano F, Casciaro E, Di Paola M, Quarta E, Muratore M and Casciaro S. (2016). Major osteoporotic fragility fractures: Risk factor updates and societal impact. World journal of orthopedics, 7 (3), 171.

[16] Dhanwal DK, Dennison EM, Harvey NC and Cooper C. (2011). Epidemiology of hip fracture: worldwide geographic variation. Indian journal of orthopaedics, 45 (1), 15.

[17] Harvey N, Dennison E and Cooper C. (2010). Osteoporosis: impact on health and economics. Nature Reviews Rheumatology, 6 (2), 99-105.

[18] Hübscher M, Vogt L, Schmidt K, Fink M and Banzer W. (2010). Perceived pain, fear of falling and physical function in women with osteoporosis. Gait and posture, 32 (3), 383-385.

[19] Hung WW, Egol KA, Zuckerman JD and Siu AL. (2012). Hip fracture management: tailoring care for the older patient. Journal of American Medical Association, 307 (20), 2185-2194.

[20] Ishikawa Y, Miyakoshi N, Kasukawa Y, Hongo M and Shimada Y. (2009). Spinal curvature and postural balance in patients with osteoporosis. Osteoporosis international, 20 (12), 2049-2053.

[21] Adachi JD, Adami S, Gehlbach S, Anderson FA, Boonen S, Chapurlat RD, Compston JE, Cooper C, Delmas P and Díez-Pérez A. (2010). Impact of prevalent fractures on quality of life: baseline results from the global longitudinal study of osteoporosis in women. In Mayo Clinic Proceedings, Elsevier, 85(9), 806-813.

[22] Suzuki N, Ogikubo 0 and Hansson T. (2009). The prognosis for pain, disability, activities of daily living and quality of life after an acute osteoporotic vertebral body fracture: its relation to fracture level, type of fracture and grade of fracture deformation. European Spine Journal, 18 (1), 77-88.

[23] Suzuki N, Ogikubo 0 and Hansson T. (2008). The course of the acute vertebral body fragility fracture: its effect on pain, disability and quality of life during 12 months. European Spine Journal, 17 (10), 1380-1390.

[24] Smulders E, Van Lankveld W, Laan R, Duysens J and Weerdesteyn V. (2011). Does osteoporosis predispose falls? A study on obstacle avoidance and balance confidence. BMC musculoskeletal disorders, 12 (1), 1.

[25] Silverman SL, Piziak VK, Chen P, Misurski DA and Wagman RB. (2005).Relationship of health related quality of life to prevalent and new or worsening back pain in postmenopausal women with osteoporosis. The Journal of rheumatology, 32 (12), 2405-2409.

[26] Madureira MM, Ciconelli RM and Pereira RM. (2012). Quality of life measurements in patients with osteoporosis and fractures. Clinics, 67 (11), 1315-1320. 
[27] Erez HB, Weller A, Vaisman N and Kreitler S. (2012). The relationship of depression, anxiety and stress with low bone mineral density in post-menopausal women. Archives of osteoporosis, 7 (1-2), 247-255.

[28] Bianchi ML, Orsini MR, Saraifoger S, Ortolani S, Radaelli G and Betti S. (2005). Quality of life in post-menopausal osteoporosis. Health and quality of life outcomes, 3 (1), 78.

[29] Mezuk B, Eaton W and Golden S. (2008). Depression and osteoporosis: epidemiology and potential mediating pathways. Osteoporosis International, 19 (1), 1-12.

[30] Abourazzak FE, Allali F, Rostom S, Hmamouchi I, Ichchou L, El Mansouri L, Bennani L, Khazzani H, Abouqal R and Hajjaj-Hassouni N. (2009). Factors influencing quality of life in Moroccan postmenopausal women with osteoporotic vertebral fracture assessed by ECOS 16 questionnaire. Health and quality of life outcomes, 7 (1), 23.

[31] Borer KT. (2005). Physical activity in the prevention and amelioration of osteoporosis in women. Sports medicine, 35 (9), 779-830.

[32] Hernlund E, Svedbom A, Ivergård M, Compston J, Cooper C, Stenmark J, McCloskey E, Jönsson B and Kanis J. (2013). Osteoporosis in the European Union: medical management, epidemiology and economic burden. Archives of osteoporosis, 8 (1-2), 136.

[33] Cosman F, De Beur S, LeBoff M, Lewiecki E, Tanner B, Randall S and Lindsay R. (2014). Clinician's guide to prevention and treatment of osteoporosis. Osteoporosis International, 25 (10), 2359-2381.

[34] Bouee S, Lafuma A, Fagnani F, Meunier P and Reginster J-Y. (2006). Estimation of direct unit costs associated with non-vertebral osteoporotic fractures in five European countries. Rheumatology International, 26 (12), 10631072.

[35] Atik OS, Gunal I and Korkusuz F. (2006). Burden of osteoporosis. Clinical orthopaedics and related research, 443, 19-24.

[36] King AB, Tosteson AN, Wong JB, Solomon DH, Burge RT and Dawson-Hughes B. (2009). Interstate variation in the burden of fragility fractures. Journal of Bone and Mineral Research, 24 (4), 681-692.

[37] Tosi LL and Kyle RF. (2005). Fragility fractures: the fall and decline of bone health. The Journal of Bone and Joint Surgery, Inc., 87(1), 1-2.

[38] Hiligsmann M, Evers SM, Sedrine WB, Kanis JA, Ramaekers B, Reginster J-Y, Silverman S, Wyers CE and Boonen A. (2015). A systematic review of cost-effectiveness analyses of drugs for postmenopausal osteoporosis. Pharmacoeconomics, 33 (3), 205-224.

[39] Lane NE. (2006). Epidemiology, etiology, and diagnosis of osteoporosis. American journal of obstetrics and gynecology, 194 (2), S3-S11.

[40] Zone C and Guide S. (2017). Postmenopausal osteoporosis. Sign, 3531 (936).

[41] Gehrig L, Lane J and O'connor MI. (2008). Osteoporosis: management and treatment strategies for orthopaedic surgeons. Journal of Bone and Joint Surgery, 90 (6), 1362-1374.

[42] Delaney MF. (2006). Strategies for the prevention and treatment of osteoporosis during early postmenopause. American journal of obstetrics and gynecology, 194 (2), S12-S23.

[43] Rachner TD, Khosla S and Hofbauer LC. (2011). Osteoporosis: now and the future. The Lancet, 377 (9773), 12761287.

[44] Kammerlander C, Gosch M, Kammerlander-Knauer U, Luger TJ, Blauth M and Roth T. (2011). Long-term functional outcome in geriatric hip fracture patients. Archives of orthopaedic and trauma surgery, 131 (10), 1435-1444.

[45] Harvey N, Dennison E and Cooper C. (2014). Osteoporosis: a lifecourse approach. Journal of Bone and Mineral Research, 29 (9), 1917-1925.

[46] Lai PSM, Chua SS and Chan SP. (2013). Impact of pharmaceutical care on knowledge, quality of life and satisfaction of postmenopausal women with osteoporosis.International journal of clinical pharmacy, 35 (4), 629637.

[47] Elias M, Burden A and Cadarette S. (2011). The impact of pharmacist interventions on osteoporosis management: a systematic review. Osteoporosis international, 22 (10), 2587. 
[48] Lötters F, Lenoir-Wijnkoop I, Fardellone P, Rizzoli R, Rocher E and Poley M. (2013). Dairy foods and osteoporosis: an example of assessing the health-economic impact of food products. Osteoporosis international, 24 (1), 139150.

[49] Reginster J-Y and Burlet N. (2006). Osteoporosis: a still increasing prevalence. Bone, 38 (2), 4-9.

[50] Melton LJ, Kanis JA and Johnell O. (2005). Potential impact of osteoporosis treatment on hip fracture trends. Journal of Bone and Mineral Research, 20 (6), 895-897.

[51] Alexandraki KI, Syriou V, Ziakas PD, Apostolopoulos NV, Alexandrakis AI, Piperi C, Kavoulaki E, Myriokefalitakis I, Korres G and Diamanti-Kandarakis E. (2008). The knowledge of osteoporosis risk factors in a Greek female population. Maturitas, 59 (1), 38-45.

\section{How to cite this article}

Ashiq K, Rehman K, Ashiq S and Sundus A. (2017). Influence of osteoporosis on quality of life and current strategies for its management and treatment. GSC Biological and Pharmaceutical Sciences, 1(2), 34-40. 